\title{
Assessing the Role of Trust in Merchant Adoption of Mobile Payments in Ghana
}

\author{
Eunice Yeboah, Richard Boateng (D), Acheampong Owusu ${ }^{(\bowtie)}(\mathbb{D})$, \\ Eric Afful-Dadzie, and Joshua Ofori-Amanfo \\ University of Ghana Business School, Box LG 78, Accra, Ghana \\ aowusu@ug.edu.gh
}

\begin{abstract}
Encouraged by the crucial need to understand merchant adoption of mobile payment, this study explores the role trust play in the adoption of mobile payment by merchant and the enablers for merchant's trust in mobile payment systems. This was done by Conceptualising the characteristics of the service provider and technology characteristics as the two dimensions that could influence merchant adoption of mobile payments. The study was done through the lenses of the Technology Acceptance Model (TAM) and the Trust-Theoretic Model and adopted a qualitative approach where two merchants were selected from the health sector. The findings demonstrate that the role of merchant trust is very critical for adoption due to m-payment technology and security risk. Hence, sufficient trust-building structures in mobile payment space are essential for the adoption of mobile payment by merchants. Moreover, the findings indicate mobile service provider characteristics and the mobile technology characteristics are both imperative toward building trust in mobile payment systems for merchants' adoption. The study also found that the trust of both technology and service provider has a far more critical influence on merchants' adoption of mobile payments than perceived usefulness or ease of use. The study, therefore, recommends that service providers should consider the opportunity to nurture merchant trust because merchant trust acts as a fundamental enabler for the adoption of mobile payments. Other implications are also discussed.
\end{abstract}

Keywords: Merchants $\cdot$ Adoption $\cdot$ M-payments $\cdot$ Trust $\cdot$ Ghana

\section{Introduction}

Mobile technology evolution and the extensive diffusion of mobile phones in performing several functions and tasks, has led to the phenomenal growth in the ownership of mobile phones globally. Notable among these everyday tasks is the use of mobile phones in making payments for goods and services without the need for cash or participation of banking institutions (Liébana-Cabanillas and Lara-Rubio 2017; Dahlberg et al. 2015; Chandra et al. 2010). This rising interest in mobile payment usage from the consumer to the merchants has become a strategic tool that facilitates positive business outcomes (Congdon 2016). Further, this innovative payment solution is considered a bedrock for competitive advantage, productivity, and growth, providing a way for businesses to achieve efficiency (Hsiao 2019). The high penetration of mobile 
payments within society, its accessibility and ease of use has led to experts classifying mobile payments as the potential payment of choice (Liébana-Cabanillas and LaraRubio 2017; Cabanillas et al. 2016). This makes mobile payments deployment relevant to the growth and development of businesses across the world (Oliveira et al. 2016). More importantly in developing countries, the mobile payment revolution is transforming households and businesses by providing a business solution to small and medium-sized businesses as well as mobile phone-related financial services to the underserved population, and help developing economies leapfrog poor non-existing payment infrastructure (Asongu et al. 2018).

Arguably, it is fascinating to observe that earlier studies on mobile payment have not fully explored the various factors that influence the behavioural intention of merchants to adopt mobile payment technology (Cabanillas et al. 2016; Dahlberg et al. 2015). Current studies on mobile payments have mostly explored technology and consumer adoption especially their implementation (Miao and Jayakar 2016; Madan and Yadav 2016). While consumer adoption studies are important in understanding mobile payments systems, researchers are of the view that an investigation of consumer adoption in isolation will not provide a full understanding of mobile payments (Dahlberg et al. 2015).

Trust, which is an essential adoption enabler in different IS situations, has not been adequately looked at in the environment of merchant adoption of mobile payment. However, mobile payments, transactions can occur among unknown entities, since mobile payments are regarded as a type of an online transaction completed over a mobile network and an accepted progression from electronic payment systems. This makes trust a significant facilitator for the merchant adoption of mobile payment (Rouibah et al. 2016). Therefore, this study seeks to understand the merchant adoption of m-payment systems and explore the trust-theoretic perspective to examine the enablers of merchant trust in mobile payment systems (Mallat 2007). The questions underpinning the study are: what is the enabler of merchant trust and what is the role of merchant trust in m-payment adoption. The remainder of this paper is structured as follows: The next section reviews the literature on mobile payments and briefly discusses the theoretical underpinnings. The third section presents the conceptual framework guiding the study; the section that follows details the methodology employed. Subsequently, the findings are analysed, and discussions of the findings presented. Finally, the paper concludes with specific contributions and directions for future research.

\section{Literature Review}

\subsection{Merchant Adoption of M-Payment Systems}

The most critical step for technology acceptance and success in technological innovations such as mobile payments is for the intended users to take the initially vital step of adoption. The vibrant nature of evolving technologies and the dynamic circumstances calls for the basic question in adoption "what factors affect the intended user to adopt various technologies?" Because research on IT innovation adoption is extensive, 
this fundamental question is examined from various dimensions such as technological, and security features, individual adopters, organisations and environment (Miao and Jayakar 2016; Dahlberg et al. 2015; Madan and Yadav 2016). Generally, scholars have used different theories to explain the adoption of innovation in technology. The study used literature on "trust" in combination with the Technology Acceptance Model (TAM) to establish a trust-theoretic model for payment adoption. TAM has been extensively used in studying IS adoption behavior (Hsiao 2019; Upadhyay and Jahanyan 2016; Merhi 2016; Shanko et al. 2016). The theory stipulates that individual's adoption of an innovation in an information system is dependent on the intention of the individual to use the system and an extent to which a customer accept that adopting an innovation will improve his effectiveness and job performance (Davis 1993; Liébana-Cabanillas et al. 2017).

Generally, using TAM is appealing in the sense that it is empirically robust, with excellent measurement qualities and dependable instruments (Davis 1993; Aboobucker and Bao 2018). Several innovation studies have validated the instructive supremacy of TAM for technology acceptance which is proven for multiple IS types (Davis 1993; Davis et al. 1989). The two key belief concepts of PU and PEOU in the theory might not sufficiently explicate the effect of additional usage issues that can influence individual intention to adopt (Davis 1993; Moon and Kim 2001). However, limited studies have examined "trust" as an additional concept. Nevertheless, trust is a fundamental concern in the mobile payment context due to the apprehensions associated with the mobile service provider and the environmental uncertainties associated with mobile technology. Chandra et al. (2010) examined trust in consumer adoption of mobile payment and the role of trust by contextualising the trust antecedents to the m-payment situation proposing a trust-theoretic m-payment adoption model. Drawing from Chandra et al. (2010), the study contextualises the antecedents of trust in mobile payment situation to merchant adoption based on the trust-theoretic m-payment adoption model.

Merchant Trust in Mobile Payments. The concept of trust has attracted a considerable amount of research due to its significant role in information systems research, especially in the e-commerce environment. Mobile payments, which are a kind of online transaction, involve virtuality, anonymity and temporal and spatial separation, which can lead to considerable uncertainty and risk. Therefore, trust is very relevant for mobile payment technology adoption. According to Zhou (2013) merchants usually have concerns about security when it comes to the use of mobile payment. Nevertheless, merchants consider trust in payment services providers and the security of mobile payment solutions as necessary criteria for the adoption of mobile payment. Therefore, it is necessary to integrate trust in examining the merchant adoption of mobile payments (Zhou 2013). Therefore, in the mobile payment environment, the two enablers of merchant trust consist of trust in provider of mobile service as well as trust in technology-enhanced by characteristics of the service provider and characteristics of the mobile technology (Chandra et al. 2010; Broutsou and Fitsilis 2012). 


\subsection{Mobile Service Provider (MSP) Characteristic}

Always, there is an affiliation between the mobile payment service provider characteristics and merchant trust as shown in Fig. 1. This can be likened to the concept of the "halo effect". The concept of the halo effect is based on the explanation that an individual's perception or views about a product or a person is based on previous experiences and the sort of interpretation which leads to cognitive bias. For instance, one can explain that Apple's other products are successful and people have confidence in it, due to the positive influence and how successful iPod was (Chong et al. 2018; Wilcox 2008). Thus, merchant perceptions on MSP as fair and honest translates to beliefs and trust for the mobile payment system controlled by the MSP. Research demonstrates that based on the halo effect, merchant trust has a positive relationship with the perceived reputation of the provider of the service, which leads to trusting beliefs in the merchant.

Therefore Proposition 1: The reputation of mobile service providers influences the level of trust the merchant has in mobile payments.

Similarly, opportunism is evident when implied and obvious possibilities around pre-determined conduct are fraudulently abused (Chong et al. 2018; John 1984). Regarding mobile payment transactions, the service provider plays a vital role, provider opportunism can be inferred as dishonest happenings such as altering information, revealing personal customer data, or deliberately unfulfilling responsibilities and promises. Therefore, merchant trust for the m-payment transaction will reduce when there is perceived opportunism. (Chong et al. 2018; Xin et al. 2013).

Thus, we propose that Proposition 2: The level of merchant trust in mobile payment systems will be reduced when there is perceived opportunism.

\subsection{Mobile Technology Characteristics}

Confidentiality and Safety concerns hamper merchant adoption of an online and wireless channel for a commercial transaction (Bhuvana and Vasantha 2017). Because of the shared domain of online information which merchants may be reluctant to adopt until they are convinced of self-assurance in the safety feature of the technology (Osakwe and Okeke 2016). In the mobile payment environment, merchants have to entrust all their account details, to MSPs and other players in the mobile payment context. Owing to the merchant's lack of control and uncertainties associated with mobile payment transactions makes merchants perceive environmental risks (Bhuvana and Vasantha 2017; Osakwe and Okeke 2016).

So, we propose that Proposition 3: The level of merchant trust in mobile payment systems are affected by Perceived environmental risk.

Nevertheless, the threat posed by mobile payment systems in comparison to traditional payment methods, stern from the technological uncertainties using the open technological infrastructure for transactions (Bhuvana and Vasantha 2017). Building suitable legal and technological safeguards can be accomplished through the development of institutional-based trust through technical procedures such as encryption of 
data and additional legal actions that avert confidentiality and monetary losses as a means of structural assurance for the mobile environment (McKnight et al. 2002). In other words, if a merchant perceived a very useful structural assurance, it will increase the level of merchant trust in mobile payment systems. Zhou (2013) and Dahlberg et al. (2015) have demonstrated that reducing the risk associated with the transaction would probably lead to the increasing adopting of mobile payments as a mode of transaction. Hence, we propose that Proposition 4: The level of merchant trust in the mobile payment system is positively influenced by perceived structural assurance.

\subsection{Adoption Intention of Mobile Payment Based on Merchant Trust}

Studies have confirmed that trust is dependent on the agency of an IT to perform a definite task (Lizcano et al. 2019; Teo et al. 2005). Regarding the mobile payment scenario, the skill is considered as the capability credence, which enables the merchants to trust that the mobile payment is suitable in attaining the anticipated objective and hence execute the intended level of performance. (Broutsou and Fitsilis 2012; Pavlou 2003). Similarly, in different online settings, individual trust is an essential element of perceived usefulness in mobile payment environment due to the uncertainties involved in such transactions and the impersonal nature of the mobile internet environment. Hence, we propose that Proposition 5: Perceived usefulness will positively influence merchant trust in mobile payment systems.

However, if there is low merchant trust in the system, it will drive the merchant to be anxious with the transactional routines (Teo et al. 2005). Which can lead to individual spending more time and effort in comprehending the system leading to systems usage challenge (Pavlou 2003; Moqbel and Bartelt 2016). Merchant trust in m-payment systems is related to perceived ease of use of $\mathrm{m}$ payment systems. As a result, we propose that Proposition 6: the extent of merchant trust in m-payment systems is related to perceived ease of use. Proposition 7: Merchant trust in m payment systems will positively influence merchant adoption of mobile payment.

According to Yang et al. (2012), the TRA indicates that 'an individual's intention to adopt an IS innovation is influenced by attitude and subjective norms, which are shaped by behavioral and normative beliefs of an individual. Trust then becomes an essential behavioral belief that generates positive attitudes to influence intention to adopt mobile payment systems, when trust is positive it is likely that merchants will likely have an intention to adopt the mobile payment system. Henceforth, merchants will adopt m-payment systems that are easy to use and will be perceived as useful. There are several benefits of M-payment systems to merchants irrespective of place and time, self-regulating transactions, which leads to effective payment transactions to the merchant. Thus, leading to an expectation that because merchant regards the mobile payment as a useful tool in achieving their purpose, they will adopt. Therefore, we propose that Proposition 8: Merchant adoption of mobile payment is positively influenced by Perceived ease of use. Proposition 9: Perceived usefulness of the m-payment systems is connected to merchant adoption of m-payment systems. 


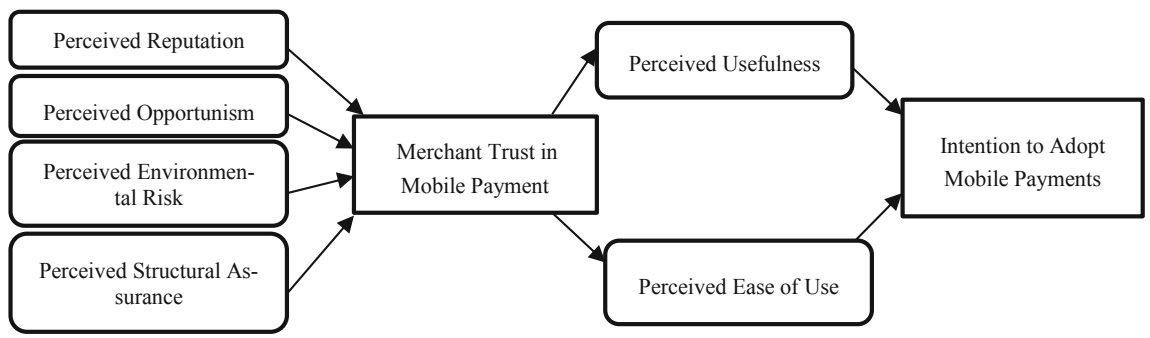

Fig. 1. Conceptual framework Source: Adopted from (Chandra et al. 2010)

\section{Methodology}

The study adopted an exploratory approach to help bring a deeper understanding of the issues under study (Saunders et al. 2012). As such, a case study was used as the research method. A case study is considered suitable for this study grounded on Yin's (2009) assertion of a case study where "why and how" questions are asked. In addition, case studies help in areas where the researcher does not have much control over the situation or where the issues under investigation are new and there is not much theory to explain issues adequately (Yin 2009). Empirical research on merchant adoption of mobile payments is spiral, in this case, the phenomenon is new and needs an in-depth understanding from the perspective of a developing country experience. The descriptive case study approach was used to enable theory to guide the data collection process (Yin 2009); as a result, the trust-theoretic stance and Technology Acceptance Model (TAM) were reviewed as the theory underpinning the case study design (Chandra et al. 2010). Face to face interview was used as a data collection method. The interview guide consisted of both open and close-ended questions. According to Walsham (1993) and Yin (2009) case study research has no universally accepted number of cases. It can be a single case or multiple cases. This research was based on a case study of two merchants from the service sector in the health industries. The case was strategically selected to enhance its external validity but not based on statistical consideration. The case was analyzed using Miles and Huberman's (2013) approach to data analysis.

\section{Results and Discussion of Findings}

\subsection{Mobile Service Provider Characteristics}

From the case finding it was established that the respondents selected the current service provider because of its brand reputation and the requisite credibility and infrastructure to deliver a reputable mobile payment service to merchants. The issue of mobile service providers' reputation was an essential trust-building mechanism in merchant adoption of mobile payment.

"It is an international company with a lot of reputation. They are credible to provide payment services, besides there is no known scandal against the service provider for all the years they have been operating the mobile money platform". The CEO of a pharmaceutical retail shop 
"My service provider, is listed on the Ghana stock exchange which makes them credible and for the period I have worked with them their services have not failed so far, it has worked well".: Director of operations in a private health facility.

These findings suggest that merchants depend on the brand name and the reputation of the service provider as risk-mitigating factors in adopting mobile payment for their business. The interviewees believe that the risk is mitigated due to the levels of authorization that the provider has in place to ensure that the rightful persons are either authorizing or originating the transaction or the exact person receiving the payment. For every transaction, you receive a message to confirm the transaction and this serves as a record to trace your transaction. Again, the respondents believe that, because there is a regulator who regulates and monitors the operations of a service provider, it will push them to do the right thing.

"I believe people do what is inspected not what is expected. We have not experienced a situation where the service provider has used our information for their selfish interest. This is because all transaction comes with notification messages to confirm the transaction". As mention by the Operations director.

These findings suggest merchants trust that, service providers have the ability and benevolence needed to provide the necessary service experience. This is because of their technological infrastructure and the legal structures that bind their operations. The merchants believe that their service providers will work within a regulated legal framework so they can be trusted to do the right things.

However, further, exploring the data retrieved from the merchants revealed that they are suspicious their service providers can behave opportunistically. This is in relation to merchant information and does not trust that their information could be safe with the service provider, because it is possible that service providers could give out personal information to the third party.

As intimated by the $\mathrm{CEO}$ "Sometimes you receive unsolicited information from the third party and you wonder how and where they get the information, which makes you think that, your service provider may have given merchant information to a third party".

This makes merchants unsure of the security of their information with the service provider, which they think could be detrimental to the business when given to your competitor. These findings suggest that the extent of merchant trust in mobile payment is influenced by the service provider reputation, however, the merchant perception of mobile service providers opportunism can reduce the level of merchant trust in $M$ payment. These finding support propositions 1 and 2 in the model.

These findings confirm earlier findings by Chandra et al. (2010) and Xin et al. (2013) on how features of the service provider and mobile payment vendor characteristics can affect trust in mobile payment adoption.

\subsection{Mobile Technology Characteristics}

On findings pertaining to mobile technology characteristics, it was discovered from the case findings that, the inherent technological risk associated with mobile payments has an influence on the adoption intention of merchants. According to the respondent, using 
mobile payment as a merchant comes with a huge risk because mobile payment operates in a wireless environment, people can steal information from the provider.

"Since it is an IT platform someone can hack into the system and delete or modify information for reasons best known to them, this makes it risky but because of its advantages it is worth the risk." As intimated by the CEO.

This assertion by merchants portrays mobile payment as potentially having significant technological risk. As such, merchants are skeptical about their information with the service provider because mobile payment is a wireless network and is susceptible to hacker attacks and intruders, which can affect transactional security. Merchants were particularly concerned about privacy, security, fraud, payment transaction errors and potential loss of cash. As a result, they did not always feel very confident in using the mobile payment for their transactions. The merchants interviewed think that mobile payment can be trusted but the risk associated with it, impacts negatively on their trust and influence their attitude which they consider a barrier to adoption of mobile payment.

\begin{abstract}
"We get all kind of calls supposedly coming from providers but it turns out to be intruders who are able to generate codes, that should be coming from service providers which are a little bit suspicious if merchant information ends up with third parties" As alluded by the operations director

"I think the encryptions back to back are not strong enough because fraudsters are able to wipe people's wallet without knowing the merchant code. I don't feel safe with the telecom company because they do not understand the banking rudiment; I will feel safe if these services are run by the banks" a statement by the operations Director
\end{abstract}

This finding is similar to earlier findings on the relationship between risk and trust (see Pavlou 2003; Osakwe and Okeke 2016; Bhuvana and Vasantha 2017). These findings support proposition 3 in the model. Additionally, the findings from the case study demonstrate that merchants are able to build confidence and sufficient trust in mobile payment systems because of structural assurance such as encryption, authentication and third-party certifications by their service providers. For example, the use of message authentication code, assures merchants and their clients that information is not tampered during transferring via networks. This ensures confidentiality, anonymity, and integrity (see Yang and Lin 2016; Xin et al. 2013). This, to a large extent, ensures the safety of the system. "I know that when I initiate a transaction nobody will be able to intercept it midway has and it gets to its destination because there is encryption for a transaction" as intimated by the CEO.

The efficient application of these technical controls helps build trust mechanisms for mobile payment systems which improve merchants' trust and confidence in mobile payment adoption intention. Further, the case findings show that proof of transactions, recipient, and assurance of user's identity helps to secure mobile payment environment without fear of compromise. This finding is also supported by our 4th proposition which states that the level of merchant trust in mobile payment systems is influenced by perceived structural assurance. 


\subsection{Perceived Usefulness}

It was identified from the case findings that merchants interviewed use the payment platform to pay their suppliers and receive payment from their clients. According to them, the companies strategically adopted mobile payment to improve the effectiveness of their business and to meet their customers' needs profitably. More importantly, the findings suggest that because the payment system is convenient and useful the merchants are prepared to ignore the risk associated with the transaction.

"The use of mobile payment has helped reduced outstanding debts because clients are able to fall on mobile payment at any time". "Since it is an IT platform someone can hack into the system and delete or modify information for reasons best known; to them, this makes it risky but because of its advantages it is worth the risk." Both respondents confirmed their usefulness.

This finding is similar to what Yang et al. (2012) found that in online payment, uncertainty risk is more or less ignored by consumers pursuing convenience and usefulness of online payment. This finding supports proposition 9 which suggests that perceived usefulness of mobile payments is associated with merchant adoption. However, this same finding points to the fact that merchant trust of mobile payment systems does not depend on perceived usefulness which means that the proposition 7 is not supported because it states that merchants trust in mobile payment systems will influence merchant adoption but the findings indicate that adoption of mobile payment does not necessarily depend on trust because trust may not signify usefulness.

\subsection{Perceived Ease of Use}

Finally, findings from the case study suggest that the functionality of the mobile payment interface by service providers through a mobile device is relatively simple and easy to navigate. They are of the view that using mobile payments for their transactions on a mobile device does not require much. The ease with which they are able to operate and understand the procedures produces a lot of confidence and builds trust that they have control of their transactions. This finding is consistent with (Lu et al. 2011). It was also observed through the case findings that merchants primarily use mobile payments to receive payments and to pay for their bills. It was evident that the level of education of merchants interviewed played a significant role in enhancing their technological literacy of mobile payment functions. Both respondents had a post-graduate degree and their staff a minimum of diploma degree.

"I am knowledgeable in all forms of electronic payment, be it internet or mobile hence mobile payment interface is easy" "We have dedicated staff who are knowledgeable in technology and are put in charge to do the mobile transactions" As commented by the merchants

This finding supports propositions 6 and 8 which indicates that the level of merchant trust in mobile payment systems has a positive influence on perceived ease of use and that merchant adoption of mobile payment is positively influenced by perceived ease of use. 


\section{Conclusion and Recommendation}

The study set out to explore the role of trust in merchant adoption of m-payment systems as well as the enablers for merchant's trust in mobile payment systems through the conceptualization of the service provider and the technology characteristics as the two dimensions that could influence merchant adoption of mobile payments. Arguably, the role of merchant trust is very significant for adoption, because of the technological risk and lack of merchant control (Yang et al. 2012; Xin et al. 2013). Hence, a sufficient trust-building mechanism is essential for merchants to adopt mobile payment. Moreover, the characteristics of the service provider of mobile payment and the mobile technology features are both imperative to build trust in mobile payment systems for merchants' adoption. The study also found that the trust of both technology and service provider has a far more critical influence on merchants' adoption of mobile payments than perceived usefulness or ease of use.

\subsection{Implications of the Study}

Implication for Theory. This study contributes to the information system literature, by establishing a relationship between merchant trust and adoption intention because merchant's acceptance and use of mobile payments is growing in recent times. Hence it is imperative to appreciate the effect of trust and how service providers can implement these technologies. These new theoretical insights will help researchers to better understand merchants trust-related antecedents and their influence on technology adoption in the context of merchant adoption of mobile payments.

Implication for Practice. Service providers should consider the opportunity to nurture and build merchant trust because merchant trust acts as a fundamental enabler for the adoption of mobile payments.

\subsection{Limitation of the Study}

The study has some limitations, it concentrated on a few variables and only done in the context of Ghana and targeted merchants who have already adopted mobile payment. Future research could compare merchants who have not yet adopted the technology with those who have adopted in context with a similar characteristic.

\section{References}

Asongu, S.A., Nwachukwu, J.C., Orim, S.M.I.: Mobile phones, institutional quality and entrepreneurship in Sub-Saharan Africa. Technol. Forecast. Soc. Change 131(November 2016), 183-203 (2018). https://doi.org/10.1016/j.techfore.2017.08.007

Aboobucker, I., Bao, Y.: What obstruct customer acceptance of internet banking? Security and privacy, risk, trust and website usability and the role of moderators. J. High Technol. Manag. Res. 29(1), 109-123 (2018) 
Bhuvana, M., Vasantha, S.: A Structural Equation Modeling (SEM) approach for mobile banking adoption-a strategy for achieving financial inclusion. Indian J. Public Health Res. Dev. 8(2), 175-181 (2017)

Broutsou, A., Fitsilis, P.: Online trust: the influence of perceived company's reputation on consumers' trust and the effects of trust on intention for online transactions. J. Serv. Sci. Manag. 5(04), 365 (2012)

Chandra, S., Srivastava, S.C., Theng, Y.-L.: Evaluating the role of trust in consumer adoption of mobile payment systems: an empirical analysis. Commun. Assoc. Inf. Syst. 29, 561-588 (2010). 27 Article

Chong, A.Y.L., Lacka, E., Boying, L., Chan, H.K.: The role of social media in enhancing Guanxi and perceived effectiveness of E-commerce institutional mechanisms in online marketplace. Inf. Manag. 55(5), 621-632 (2018)

Congdon, S.: What's in your wallet: addressing the regulatory grey area surrounding mobile payments. Case W. Res. JL Tech. Internet 7, 95 (2016)

Dahlberg, T., Guo, J., Ondrus, J.: A critical review of mobile payment research. Electron. Commer. Res. Appl. 14(5), 265-284 (2015)

Davis, F.D.: User acceptance of information technology: system characteristics, user perceptions and behavioral impacts. Int. J. Man-Mach. Stud. 38(3), 475-487 (1993)

Davis, F.D.: Perceived usefulness, perceived ease of use, and user acceptance of information technology. MIS Q. 13(3), 318-339 (1989)

Davis, D., Bagozzi, R.P., Warshaw, P.R.: User acceptance of computer technology: a comparison of two theoretical models. Manag. Sci. 35(8), 982-1003 (1989)

Hsiao, M.H.: Mobile payment services as a facilitator of value co-creation: a conceptual framework. J. High Technol. Manag. Res. 30(2), 100353 (2019)

John, G.: An empirical investigation of some antecedents of opportunism in a marketing channel. J. Market. Res. 21, 278-289 (1984)

Liébana-Cabanillas, F., Lara-Rubio, J.: Predictive and explanatory modeling regarding adoption of mobile payment systems. Technol. Forecast. Soc. Chang. 120, 32-40 (2017)

Liébana Cabanillas, F., Slade, E., Dwivedi, Y.: Time for a different perspective: a preliminary investigation of barriers of merchants' adoption of mobile payments (2016)

Liébana-Cabanillas, F., Ramos de Luna, I., Montoro-Ríos, F.: Intention to use new mobile payment systems: a comparative analysis of SMS and NFC payments. Econ. Res. 30(1), 892910 (2017)

Lu, Y., Yang, S., Chau, P.Y., Cao, Y.: Dynamics between the trust transfer process and intention to use mobile payment services: a cross-environment perspective. Inf. Manag. 48(8), 393-403 (2011)

Lizcano, D., Lara, J.A., White, B., Aljawarneh, S.: Blockchain-based approach to create a model of trust in open and ubiquitous higher education. J. Comput. High. Educ. 31, 1-26 (2019)

Madan, K., Yadav, R.: Behavioural intention to adopt mobile wallet: a developing country perspective. J. Indian Bus. Res. 8(3), 227-244 (2016). https://doi.org/10.1108/JIBR-10-20150112

Mallat, N.: Exploring consumer adoption of mobile payments - a qualitative study. J. Strateg. Inf. Syst. 16, 413-432 (2007)

McKnight, D.H., Choudhury, V., Kacmar, C.: Developing and validating trust measures for ecommerce: an integrative typology. Inf. Syst. Res. 13(3), 334-359 (2002)

Merhi, M.I.: Towards a framework for online game adoption. Comput. Hum. Behav. 60, 253263 (2016)

Miao, M., Jayakar, K.: Mobile payments in Japan, South Korea and China: cross-border convergence or divergence of business models? Telecommun. Policy 40(2-3), 182-196 (2016) 
Miles, M.B., Huberman, A.M., Saldana, J.: Qualitative Data Analysis: A Methods Sourcebook. SAGE Publications, Incorporated, Thousand Oaks, California (2013)

Moqbel, M.A., Bartelt, V.L.: Open data discourse: consumer acceptance of personal cloud: Integrating trust and risk with technology acceptance model. Trans. Replication Res. 2, 1-8 (2016)

Moon, J.W., Kim, Y.G.: Extending the Tam for a World-Wide-Web context. Inf. Manag. 38(4), 217-230 (2001)

Oliveira, T., Thomas, M., Baptista, G., Campos, F.: Mobile payment: understanding the determinants of customer adoption and intention to recommend the technology. Comput. Hum. Behav. 61, 404-414 (2016)

Osakwe, C.N., Okeke, T.C.: Facilitating mCommerce growth in Nigeria through mMoney usage: a preliminary analysis. Interdisc. J. Inf. Knowl. Manag. 11, 115-139 (2016)

Pavlou, P.A.: Consumer acceptance of electronic commerce-integrating trust and risk with the technology acceptance model. Int. J. Electron. Commer. 7(3), 101-134 (2003)

Rouibah, K., Lowry, P.B., Hwang, Y.: The effects of perceived enjoyment and perceived risks on trust formation and intentions to use online payment systems: new perspectives from an Arab Country. Electron. Commer. Res. Appl. 19, 33-43 (2016)

Saunders, M., Lewis, P., Thornhill, A.: Research Methods for Business Students, 6th edn. Pearson Education Limited, Noida (2012)

Shanko, G., Negash, S., Bandyopadhyay, T.: Mobile healthcare services adoption. Int. J. Netw. Virtual Organ. 16(2), 143-156 (2016)

Teo, E., Fraunholz, B., Unnithan, C.: Inhibitors and facilitators for mobile payment adoption in Australia: a preliminary study. In: International Conference on Mobile Business (ICMB 2005), pp. 663-666. IEEE, July 2005

Upadhyay, P., Jahanyan, S.: Analyzing user perspective on the factors affecting use intention of mobile based transfer payment. Internet Res. 26(1), 38-56 (2016)

Walsham, G.: Interpreting Information Systems in Organizations, vol. 19. Wiley, Chichester (1993)

Wilcox, J.: The iPhone Halo Effect. Apple Watch—eweek.com, 22 August 2008. http://blogs. eweek.com/applewatch/content/mac_os_x/the_iphone_halo_effect.html

Xin, H., Techatassanasoontorn, A.A., Tan, F.B.: Exploring the influence of trust on mobile payment adoption (2013)

Yang, J.H., Lin, P.Y.: A mobile payment mechanism with anonymity for cloud computing. J. Syst. Softw. 116, 69-74 (2016)

Yang, S., Lu, Y., Gupta, S., Cao, Y., Zhang, R.: Mobile payment services adoption across time: an empirical study of the effects of behavioral beliefs, social influences, and personal traits. Comput. Hum. Behav. 28(1), 129-142 (2012)

Yin, R.K.: Case Study Research, Design and Methods, 3rd edn. Sage Publications, Newbury Park (2009)

Zhou, T.: An empirical examination of continuance intention of mobile payment services. Decis. Support Syst. 54(2), 1085-1091 (2013) 